\title{
Dispositivos de cancelación del psicopoder
}

Jonathan E. Prueger ${ }^{1}$

Recibido: 29/07/2021; Aceptado: 18/09/2021

Cómo citar: Prueger, J. E. (2021) Dispositivos de cancelación del psicopoder. Revista Hipertextos, 9(16), 99-114. https://doi.org/10.24215/23143924e042

Resumen. Entre uno de los auges que caracterizaron al primer año pandémico, encontramos el aumento de referencias -alusiones- a lo que se ha dado en llamar "cultura de la cancelación". En el presente artículo me propongo abordar analíticamente a la cancelación como un nuevo dispositivo del poder, desde el espectro teórico postdisciplinario (Prueger, 2020a) y en clave descolonial. Si se trata de superar las limitaciones epistémicas de la modernidad occidental, Simondon (2009) -aunque francés- constituye un autor que tiene muchísimo para aportar. Al interior del espectro postdisciplinario, los registros simondonianos del poder dan cuenta de la cristalización digital de un nuevo marco epistémico; las dinámicas del psicopoder exigen ser analizadas a la luz de una nueva episteme en tiempos de gubernamentalidad algorítmica (Rouvroy y Burns, 2016). En los trasfondos de los dispositivos de cancelación (propuesta teórico-analítica que pretendo describir en el presente artículo) y de la gubernamentalidad algorítmica encontramos el mismo principio ordenador (el mismo horizonte en común): la eliminación del principio de alteridad. Luego será precisar: elementos en torno al modo de operar de los dispositivos de cancelación -particularmente lo que respecta a la catalización catártica-; tendencias predominantes en lo que hace al registro ideológico-cultural; por último, algunas reflexiones en torno a este fenómeno en el marco de la actual crisis sistémica y encrucijada civilizatoria que atraviesa la humanidad.

Palabras clave: cancelación, control, postdisciplinario, gubernamentalidad, dividual

Sumario. 1. Auge pandémico de la "cultura de la cancelación”. 2. Imperativos morales y exclusión radical. 3. Modo de operar de los dispositivos de cancelación. 4. Episteme simondoniana, psicopoder y dispositivos de cancelación. 5. Registro ideológico-cultural preponderante de los dispositivos de cancelación. 6. Una propuesta de abordaje de la alteridad.

\section{Psychopower cancellation devices}

Abstract. Among one of the booms that characterized the first pandemic year, we find the increase in references - allusions - to what has been called the "culture of cancellation". In this article, I intend to analytically approach cancellation as a new device of power, from the postdisciplinary theoretical spectrum

${ }^{1}$ Lic. en Sociología (FaHCE-UNLP). Integrante del PPID "Dependencia epistémica, eurocentrismo y colonialidad del saber: hacia un pensamiento situado" (FTS-UNLP) y el proyecto "Datos, algoritmos y plataformas. Las nuevas formas de la gubernamentalidad a la luz de la teoría de lo transindividual de G. Simondon" del IIGG-UBA. Contacto: ejprueger@gmail.com 
(Prueger, 2020a) and in a decolonial key. When it comes to overcoming the epistemic limitations of Western modernity, Simondon (2009) -although French- is an author who has a lot to contribute. Within the postdisciplinary spectrum, Simondonian registers of power account for the digital crystallization of the new epistemic framework; the dynamics of psychopower demand to be analyzed in the light of a new episteme in times of algorithmic governmentality (Rouvroy and Burns, 2016). In the background of cancellation devices (analytical proposal that I intend to describe in this article) and algorithmic governmentality, we find the same ordering principle (the same common horizon): the elimination of the principle of otherness. Then I will specify: elements around the mode of operation of cancellation devices -particularly with regard to cathartic catalysis-; predominant tendencies regarding the ideological-cultural register; finally, some reflections on this phenomenon in the context of the current systemic crisis and civilizational crossroads that humanity is going through.

Keywords: cancellation, control, post-disciplinary, governmentality, dividual

\section{Dispositivos de cancelamento de psicopoder}

Resumo. Entre um dos booms que caracterizaram o primeiro ano de pandemia, encontramos o aumento das referências - alusões - ao que se convencionou chamar de "cultura do cancelamento". Neste artigo, pretendo abordar analiticamente o cancelamento como um novo dispositivo de poder, a partir do espectro teórico pós-disciplinar (Prueger, 2020a) e em uma chave descolonial. No que diz respeito à superação das limitações epistêmicas da modernidade ocidental, Simondon (2009) -embora francês- é um autor que tem muito a contribuir. No espectro pós-disciplinar, os registros de poder Simondonianos respondem pela cristalização digital da nova estrutura epistêmica; a dinâmica do psicopoder exige ser analisada à luz de uma nova episteme em tempos de governamentalidade algorítmica (Rouvroy e Burns, 2016). No pano de fundo dos dispositivos de cancelamento (proposta analítica que pretendo descrever neste artigo) e da governamentalidade algoritmica, encontramos o mesmo princípio ordenador (o mesmo horizonte comum): a eliminação do princípio da alteridade. Em seguida, especificarei: elementos em torno do modo de operação dos dispositivos de cancelamento -particularmente no que diz respeito à catálise catártica-; tendências predominantes quanto ao registro ideológico-cultural; por fim, algumas reflexões sobre este fenômeno no contexto da atual crise sistêmica e encruzilhada civilizacional pela qual a humanidade está passando.

Palavras-chave: cancelamento, controle, pós-disciplinar, governamentalidade, dividual.

\section{Auge pandémico de la "cultura de la cancelación"}

En el último año es posible identificar cómo la referencia a lo que se ha dado en llamar 'cultura de la cancelación' es cada vez más frecuente en la opinión pública. El año pasado, en Estados Unidos, 153 intelectuales (entre las figuras de mayor renombre: Noam Chomsky, Saldman Rudshie, Margaret Atwood y Javier Cercas) firmaron una carta en contra de la "cultura de cancelar". Dicha carta afirma que el "libre intercambio de información e ideas, la savia de las sociedades liberales, está cada día más constreñido”. Para los firmantes las posibilidades del desacuerdo peligran, lo cual es un problema: siendo necesarios "los desacuerdos de buena fe sin que tengan terribles consecuencias profesionales".

\footnotetext{
2 https://www.lavanguardia.com/cultura/20200709/482194746019/intelectuales-contra-cultura-cancelacionintolerancia-discrepar.html
}

Hipertextos, Vol. 9, N 16. Buenos Aires, Julio/Diciembre de 2021 «100 https://doi.org/10.24215/23143924e042, https://revistas.unlp.edu.ar/hipertextos 
Particularmente en Argentina, encontramos un considerable aumento ${ }^{3}$ de notas periodísticas que abordan el tema en lo que va de la pandemia del COVID-19 (Cuello y Disalvo, 2020; Mariño, 2020; Moscato, 2021; Grosso, 2021; por dar algunos ejemplos). Esto no quiere decir que constituya un fenómeno reciente. Pero sí nos puede sugerir que la profundización pandémica de la mediación digital de las distintas esferas de la vida social ${ }^{4}$, sumado a una radicalización de las posturas político-ideológicas debido a la crisis económica y las nuevas legislaciones y normatividades pandémicas, podrían estar dando lugar a la consolidación de una nueva modalidad del poder.

Si bien dicho fenómeno no está restringido a un solo registro ideológico-cultural, no son pocos los autores que identifican una preponderancia de posturas de corte progresista-liberal, progresista a secas o de izquierda progresista. Vienen emergiendo algunas discursividades y prácticas -desde algunos feminismos, antirracismos y ecologismos particulares- con una mayor tendencia hacia formas de punitivismo social y exclusión radical (Foucault, 2002). A ello le dedicaremos un apartado especial.

Resulta necesario poner este fenómeno contemporáneo bajo la lupa de ciertas analíticas del poder. Desde las herramientas que nos brindan las teorías del poder postdisciplinarias (Prueger, 2020a) me propongo en el presente trabajo un análisis de la llamada "cultura de la cancelación" como un nuevo dispositivo ${ }^{5}$ del psicopoder.

\section{Imperativos morales y exclusión radical}

Los dispositivos de cancelación operan en la sociedad suscitando la reactualización de imperativos categóricos morales en torno a las conductas, donde se ponen en marcha tanto dinámicas de vigilancia como punitivas. El tipo de vigilancia propio de nuestras sociedades postdisciplinarias, siguiendo a Han (2014), es postpanóptica. Siguiendo a Bruno (2013) se trata de una vigilancia "distribuida e inmanente". Es decir, que en su forma paradigmática predomina una generalización de la vigilancia en la sociedad; una vigilancia mutuamente garantizada por los integrantes de una sociedad. La estructuración morfológica del ciberespacio y fundamentalmente las redes sociales ${ }^{7}$-pilares de la vigilancia postpanóptica- contribuyen al cumplimiento del mandato de la transparencia: todo debe estar expuesto, todo debe ser visible.

\footnotetext{
${ }^{3}$ Invitamos al lector a dirigirse al portal de "Google", buscar "cultura de la cancelación" y observar cómo la mayoría abrumadora de publicaciones sobre el tema son del año 2020 y el corriente (2021).

4 Desde el barómetro del consumidor de Google, la CEPAL y otros portales como COMSCORE (https://www.comscore.com/lat/Prensa-y-Eventos/Comunicados-de-prensa/2021/2/Consumo-digital-2020-enLatinoamerica) identifican un notorio aumento tanto de los tipos como de las cantidades de consumos digitales durante el primer año de pandemia.

5 En el registro teórico foucaultiano/postfoucaultiano, tanto la idea de tecnología como la de dispositivo refieren a la orientación estratégica -es decir, en lo que respecta a la dimensión del poder- de un conjunto heterogéneo de procedimientos, hábitos, modos, prácticas, instituciones, discursos, etc.; los cuales afectan ciertos modos de ser y saber, que -a su vez- son afectados por estos.

${ }^{6}$ Cuando hablamos de psicopoder nos referimos al conjunto de tecnologías del poder psicopolíticas (Han, 2018a) y noopolíticas (Lazzarato, 2006) que caracterizan a nuestras actuales sociedades postdisciplinarias. Políticas sígnicas, mediadas por la digitalidad, que buscan ocupar una determinada temporalidad de nuestra subjetividad y dejar huella en la memoria. Políticas de la psique y el inconsciente (individual y colectivo) que tienden a afectar nuestras inclinaciones y predisposiciones en dirección a confundir la dominación con la más plena libertad. Dedicó especial atención a la caracterización y sistematización de las tecnologías del psicopoder (psicopolíticas/noopolíticas) en un reciente artículo publicado en la Revista Hipertextos (Prueger, 2020b).

7 Otra de las hipótesis de este trabajo es que la llamada 'cultura de la cancelación' o, siguiendo la propuesta aquí expuesta, los dispositivos de cancelación constituyen un fenómeno distintivamente contemporáneo. Si bien las tendencias
} 
Siempre resultó revelador poder analizar el lugar de ciertos imperativos morales en las distintas configuraciones societales del poder. Por dar un ejemplo clásico, podemos referirnos a los mandatos de productividad y ascetismo propios de la Reforma Protestante, siguiendo las huellas de Max Weber (1979). Hacia nuestros tiempos nos encontramos ante nuevos mandatos y otros modificados. Al ya enunciado mandato de la transparencia se le suman: rendimiento, positividad, hedonismo y narcisismo (Prueger, 2020b).

Un conjunto amplio de autores viene planteando que las sociedades neoliberales occidentales manifiestan una tendencia ascendente hacia la eliminación de la negatividad. El mandato de la positividad tiende a expulsar, tanto de los planos intraindividuales como de los interindividuales (o colectivos) $^{8}$, todo elemento de disparidad, alteridad, contradicción. El desarrollo y generalización de las TIC's (Tecnologías de la Información y la Comunicación), la profundización de la mediación digital de las distintas esferas de la vida social, contribuyen ampliamente al cumplimiento de la utopía positivista de la eliminación de la negatividad. En las lógicas y horizontes que regulan las plataformas digitales y el ciberespacio en general, ello es reconocido por Pasquinelli y Joler (2021) como el modo en que el aprendiaje maquinico se proyecta, desde la predictibilidad y la performatividad inconsciente, a la regeneración de lo viejo; limitando las posibilidades de un nuevo evento histórico (p. 11). Rouvroy y Burns (2016) refieren a una "pérdida de la pérdida propia de la modelización digital de los posibles, la cual priva de su potencia de interrupción, de cuestionamiento, a lo que podría surgir desde el mundo en su disimetría respecto de la realidad"10 (p. 114).

El alcance, intensidad, sutileza y eficacia del psicopoder logra volver los imperativos morales inclinación inconsciente de los sujetos. Sin embargo, lo cierto es que la eliminación de la alteridad no sólo se expresa en la capacidad de los dispositivos de gubernamentalidad algoritmica ${ }^{11}$ de accionar en planos infra y supraindividuales. La interpelación discursiva a un sujeto no ha dejado de existir (lo cual será abordado más adelante), ni mucho menos. En lo que respecta a los discursos, proliferan aquellos que contribuyen al cumplimiento del imperativo categórico de la positividad, por ejemplo: en las propuestas políticas neoliberales de la segunda década del s. XXI en América Latina, en las áreas del coaching, el emprendedorismo, la autoayuda y una parte importante de las

en función de la eliminación de la alteridad no son ninguna novedad, y es posible rastrear los antecedentes de la cancelación en el 'escrache' y el 'linchamiento', las particularidades de este fenómeno se encuentran estrechamente vinculadas a la "revolución digital” (Ceceña, 1996; Martins, 2011), el "capitalismo de plataformas" (Srnicek, 2018) o “cognitivo”(Rullani, 2004; Zukerfeld, 2006) y lo que el máximo exponente del Foro Económico Mundial de Davos ha dado en llamar la "Cuarta Revolución Industrial” (Schwab, 2016)

${ }^{8}$ En lugar de referirnos a planos intraindividuales e interindividuales, sería mucho más preciso hablar de lo dividual (Deleuze, 1994; Rodríguez, 2019) y lo transindividual (Simondon, 2009), en el marco de la propuesta epistémica simondoniana y su afinidad con las formas y despliegues del psicopoder. Dedicaremos un apartado específico a este tema ya que -además- cobra una particular relevancia a la hora de reflexionar en torno al modo de operar de los dispositivos de cancelación.

9 "La predicción por aprendizaje maquínico se utiliza para proyectar tendencias y comportamientos futuros de acuerdo a los del pasado, es decir, para completar una pieza de la información conociendo solo una parte de ella” ( $p$. 9)

10 En el planteo de dichos autores, "la realidad" constituye algo en mayor medida mediado y preformado por la digitalidad y -particularmente- el gobierno de los datos; mientras que "el mundo" representaría la totalidad compleja y contradictoria que nunca logra ser reducida del todo a la digitalidad.

11 Siguiendo a Rouvroy y Burns (2016): "Llamamos gubernamentalidad algorítmica, globalmente, a un cierto tipo de racionalidad (a)normativa o (a)política que reposa sobre la recolección, la agrupación y el análisis automatizado de datos en cantidad masiva de modo de modelizar, anticipar y afectar por adelantado los comportamientos posibles" (p. 96). Particularmente la dataveillance (vigilancia de datos) refiere al relevamiento y almacenamiento automatizado de datos, mientras que el datamining constituye el momento de la identificación automática de correlaciones entre los datos, en cantidades colosales. 
espiritualidades New Age (Pastor, 2020). Sumado a esto, la morfología que estructura las dinámicas de las plataformas digitales tiende a devolver una imagen del mundo "con capacidad de ajustarse permanentemente a cada subjetividad". De esta manera "se va configurando un círculo de espejos, donde el sujeto no deja de encontrarse a sí mismo en la imagen del mundo que recibe" (Prueger, 2020b); lo cual contribuye a la configuración de una subjetividad narcisista e intolerante ante la alteridad.

Las modalidades del psicopoder logran cada vez más que el imperativo de la positividad sea suscitado y reactualizado -tanto consciente como inconscientemente- por los sujetos mismos. Ya no son impuestos desde una normatividad coactiva disciplinante. Estamos ante un psicopoder que construye e interpela un ideario de sujeto, el cual es también un psicopoder cuya mayor astucia consiste en un tipo de influencia que se erige sobre nuestras inclinaciones y predisposiciones inconscientes. Prever y modular ${ }^{12}$, tanto en planos intraindividuales como supraindividuales. La digitalización ascendente de las distintas esferas de la vida social, de la mano con las dinámicas propias de la gubernamentalidad algoritmica, aportan a concretar aquel escenario donde dominación y libertad se confunden cada vez más (Prueger, 2020a: 70).

Deleuze anticipó algo en Posdata a las sociedades de control (1991): "puede ser que viejos medios, tomados de las sociedades de soberanía, vuelvan a la escena, pero con las adaptaciones necesarias" (p. 4). Luego, algunos autores vieron esto expresado en el regreso de la 'espectacularización del castigo', a partir del desarrollo y generalización de las TIC's. Hacía nuestros días, hablar de espectacularización del castigo restaría mucho más de lo que sumaría; en tanto la espectacularización constituye -ascendentemente- un elemento intrínseco de nuestras sociedades actuales de control digital ${ }^{3}$. Sin descartar, por ello, la necesidad de indagar en torno a la forma en que se expresa la espectacularización en los dispositivos de cancelación del psicopoder. Sin embargo, en la misma línea que trazó Deleuze, una de las hipótesis de este artículo es que los dispositivos de cancelación constituyen una reactualización de lo que describiera Foucault (2002) como las políticas de exclusión radical propias de un poder soberano. Esta vez, de la mano de las tecnologías del poder psicopolíticas/noopoliticas.

\section{Modo de operar de los dispositivos de cancelación}

Los dispositivos de cancelación tienden hacia una modalidad de exclusión radical, una forma de expulsión social definitiva. Esto arrastra un conjunto de implicancias en torno a las dinámicas colectivas legítimas de nuestras sociedades (sobre las cuales arriesgaremos algunas descripciones generales). Si bien los dispositivos de cancelación no implican el aniquilamiento o exilio físicos ${ }^{14}$, la

\footnotetext{
12 Afectar ajustando y reajustando dicha influencia en el movimiento, en el devenir. Así en Deleuze como en Simondon, la modulación refiere a una suerte de influencia no estática, la cual se actualiza constantemente en el devenir. Desde las perspectivas del poder constituye, además, un afectar sin dar órdenes, a partir del establecimiento de rangos de acción posibles. Para ampliar en ello, basta con el mapa teórico al que Pablo Rodríguez (2019: 362) le dedicó un apartado en Las palabras en las cosas.

13 Quizás estemos ante un tiempo propicio para desempolvar algunas intuiciones de Baudrillard (1978 y 1999), que en su momento no encontraron tanto eco: algo del cambio de eje analítico desde el poder a la seducción y su propuesta de la procesión de los simulacros.

14 Aunque, en no pocos casos, sí pueden implicar la expulsión de instituciones y espacios de pertenencia social que no se limitan al ciberespacio.
} 
muerte digital podría significar un modo de exclusión radical; fundamentalmente teniendo en cuenta que en nuestros tiempos la existencia digital tiende a detentar rango de $\operatorname{ser}^{15}$.

No pocas veces la cancelación constituye una alternativa civil ante la ineficacia y complicidad de las instituciones judiciales de los estados con los poderes fácticos. A diferencia de la cancelación digital, el juicio y castigo estatal supone una evaluación del daño infringido -en torno a marcos normativos establecidos- y la determinación de una compensación y/o castigo correspondiente a dicho daño. El enjuiciamiento y el castigo jurídico moderno (disciplinario) no implica una expulsión, en tanto la persona es integrada a una determinada institución que se encarga de efectivizar el castigo y la normalización correspondiente. Los dispositivos de cancelación no operan desde ningún marco normativo formalmente establecido, sino desde iniciativas que emergen con cierto grado de autonomía en la sociedad, siendo proyectadas desde las redes sociales y los medios masivos de comunicación ${ }^{16}$.

En términos discursivos logra erigirse un sentido común determinado. Vuelven a emerger discursos de una fuerte impronta moralista y moralizante, pero en una nueva modalidad y registro ideológico-cultural. En lo que respecta a la modalidad, ya no constituye una obligatoriedad normativa de un poder disciplinario o un poder soberano. Más bien suscita dinámicas espontáneas de autorregulación de la dominación en el seno mismo de la sociedad, con un gran protagonismo de las plataformas digitales (las redes sociales principalmente) ${ }^{17}$.

Si quisiéramos distinguir el modo en que operan los dispositivos de cancelación podríamos hablar de un primer momento de señalamiento de la falta (del crimen, de la inmoralidad, etc. ${ }^{18}$ por parte de un agente hacia otro, y en un determinado lugar: el cual confluye en el ciberespacio. Una dinámica signada por el contagio digital ${ }^{19}$ y el juzgamiento moral condensan un segundo momento de enunciación y legitimación de un discurso 'intersubjetivo' en el cual se pregona la inadmisibilidad de determinada conducta $^{20}$. A ello le es contiguo y sucede una instancia de denuncia, condena y linchamiento digital, lo cual configura el escenario final de la cancelación o muerte digital.

15 Resulta más que probable que la muerte digital tenga implicancias en el registro de las corporalidades: tanto del cuerpo social general (biopolítica), como los cuerpos individuales (anatomopolítica); sus flujos de circulación. Sin embargo, el alcance de este trabajo se limita a lo que respecta particularmente al psicopoder.

${ }^{16}$ En la cuarta edición del Encuentro Latinoamericano de Feminismos, Rita Segato llamó la atención en torno a la necesidad de diferenciar las modalidades de los primeros escraches de otras formas de linchamiento. Así lo reconstruye Alfie (2018), para una nota de la Agencia Paco Urondo:

“estos métodos usados en el período de post-dictadura 'nunca fueron un linchamiento', sino el fruto de 'un convenio colectivo a través del cual concluyeron que había que llegar a un castigo': aunque no hubo una instancia judicial, sí hubo una de 'juicio justo'. Por eso reconoce que 'desde el feminismo podría haber una instancia de juicio justo' -en vez de los escraches como se los conoce ahora-, 'como una asamblea, para que la situación no sea un linchamiento sin sumario'. 'Si defendemos el derecho al proceso de justicia, nuestro movimiento no puede proceder de esa forma que ha condenado"”

17 Los Medios Masivos de Comunicación también cumplen un importante rol en la puesta en agenda y reforzamiento de los sentidos comunes que suscitan los dispositivos de cancelación.

${ }_{18} \mathrm{Al}$ respecto de este primer momento, resulta necesario aludir a cierta aparente afinidad entre el fenómeno de la cancelación con lo que se ha dado a conocer con el neologismo de 'posverdad' (Roberts, 2010). Por razones de extensión no me detendré en dicha afinidad, la cual sin duda merece una especial atención.

${ }^{19}$ Fue Tarde (1986), a fines del s. XIX, el primero en recurrir a la idea de 'contagio' a la hora de caracterizar el surgimiento de unas nuevas dinámicas del poder (el gobierno de los públicos), a partir del todavía incipiente desarrollo de las 'TIC's.

${ }^{20}$ En relación a las teorías de la desviación, la propuesta de abordaje desde el interaccionismo simbólico (Becker, 2009) requiere ser revisada ante la efectivización sociodigital de una nueva episteme (Simondon, 2009; Rouvroy y Burns, 2016) que nos exige descartar toda noción de interacción que suponga sujetos preconstituidos. A la hora de preguntarnos en torno a las dinámicas colectivas en nuestros tiempos, es necesario subvertir el marco epis témico de la modernidad. A ello dedicaré una buena parte del próximo apartado.

Hipertextos, Vol. 9, N 16. Buenos Aires, Julio/Diciembre de 2021 «104 https://doi.org/10.24215/23143924e042, https://revistas.unlp.edu.ar/hipertextos 
Por otro lado, los dispositivos de cancelación permiten configurar catalizadores catárticos de la indignación, malestar e insatisfacción social. Permiten ubicar los problemas de nuestras sociedades en sujetos concretos a los cuales se puede expulsar; cual intervención médico quirúrgica que permite extirpar de un cuerpo sano el elemento disfuncional (un apéndice infectado, por ejemplo). Sostiene un entramado ideológico-cultural donde: el problema se encuentra en los demás (y no dentro mío también); se resuelve con la expulsión de sujetos concretos; por último, no se ponen en crisis las dimensiones sistémicas y civilizatorias que generan y enmarcan dichas conductas.

La catalización catártica de los dispositivos de cancelación permite que se exprese, condense y dirija hacia un sujeto/objeto específico el rechazo a elementos que forman parte intrínseca de nuestras sociedades. Es una descarga controlada y refuncionalizada de negatividad emocional-afectiva: particularmente en lo que respecta a las experiencias de malestar e insatisfacción inherentes a nuestras sociedades neoliberales contemporáneas. La idea de 'chivo expiatorio' podría adquirir alguna utilidad al respecto. A partir de cierto consenso social digital (condena digital), se generan las condiciones de apañamiento que posibilitan la expresión de emociones y afectividades que de otro modo no sería legítimo expresar. La alteridad -si existe- puede ser denunciada, embestida, acosada y cancelada hasta provocar la muerte digital. En el marco de aquello que constituye una de las particularidades de las dinámicas del psicopoder, dicho dispositivo suele ser suscitado con un amplio margen de participación de la sociedad en su surgimiento y expansión. Allí es donde cumplen un papel clave el ciberespacio y las plataformas digitales (en términos de condiciones materiales de la sociabilidad contemporánea); y el interpelamiento moral correspondiente.

Cerraré este apartado con un ejemplo. Vengo relevando información sobre las repercusiones de un caso donde un joven de unos 22 años es filmado por unas cámaras de seguridad pateando fuertemente a un perro caniche, en la ciudad de La Plata (Argentina). Lo registrado fue expuesto en redes sociales digitales y allí comenzó el momento de señalamiento (de la falta, del crimen, de la inmoralidad etc.). El caso va ganando capacidad de viralización en la misma medida que el juzgamiento moral es motor de iniciativas digitales de todo tipo: compartir sus cuentas de redes sociales, exposición del rostro e invitación a no olvidarlo, invitaciones a ejercer acoso digital, comunicados de instituciones a las cuales pertenece y es expulsado, entre otros. Se consolida un marco de consenso social digital (condena digital) que legitima un conjunto de expresiones y prácticas determinadas, las cuales podrían ir dando por resultado una forma de exclusión radical: la muerte digital.

El joven protagonista de este caso de maltrato animal fue objeto de las siguientes alusiones ${ }^{21}$ : "Por favor les pido, compartan este perfil. Escrache a este ser humano de mierda"; "Te mereces lo peor"; "No tiene que laburar nunca más esta basura. Condena social"; "Desinstaló WhatsApp, pero pueden mandarle un "lindo mensajito' [SMS]"; "No se olviden de esta cara".

\section{Episteme simondoniana, psicopoder y dispositivos de cancelación}

En los últimos años es posible identificar la concretización digital (ciberespacial) de dinámicas del poder que se desenvuelven siguiendo los lineamientos de una nueva episteme (Rodríguez, 2019). Siempre enfrentamos las limitaciones de mirar con las anteojeras y el lenguaje del pasado las problemáticas y dilemas del presente (lo cual abona a su perpetuación). En este sentido, se va haciendo cada vez más clara la relevancia ontológica y epistémica de la propuesta simondoniana

${ }^{21}$ Por razones obvias, no daremos a conocer los nombres de los autores de dichas manifestaciones. 
a la hora de reflexionar en torno a las transformaciones en curso en nuestras sociedades (Simondon, 2009).

Dicha propuesta, a mediados del siglo XX, sopesando las implicancias de los descubrimientos en torno a la mecánica cuántica, arremete contra el hilemorfismo sobre el que se afirma la episteme moderna. El hilemorfismo aristotélico constituye una premisa filosófica y ontológica que plantea la diferenciación entre materia y forma, quedando del lado de la materia la substancia (fundamento del materialismo científico moderno), la cual mantiene rango de ser, y dando por condición dada a la individuación. Es decir, se da por sentado la existencia de individuos; en los diversos planos en los que se los pueda concebir.

En los fundamentos ontológicos de la episteme moderna, la individuación es punto de partida y condición dada; no se indaga en la ontogénesis de los individuos (ya sean piedras, moléculas de ARN, átomos, plantas, vacas o seres humanos). Frente a las nociones de forma y substancia -y sus evidentes limitaciones epistémicas para las ciencias ${ }^{22}$ - Simondon plantea la superioridad de las nociones de información y comunicación. Proponiendo una episteme que encuadre y describa el devenir del ser, en lugar de una episteme que da por sentado el ser, y -por lo tanto- su ontogénesis. Desde la segunda década del siglo XX, ya contábamos con desarrollos científicos en distintos campos que estaban logrando acercamientos en dicha dirección, valiéndose de las mismas categorías: información, comunicación, código, sistema, signo, entre las principales.

Simondon conceptualiza el surgimiento de un nuevo marco epistémico general que supera la fragmentada episteme moderna ${ }^{23}$. Dicho marco detenta el potencial de dar cuenta de la ontogénesis de la individuación físico-química, vital, psíquica y psíquico-colectiva o transindividual (nueva propuesta de lo social empírico a describir). Indaga más allá de la órbita de lo aparentemente estable, dando cuenta del carácter metaestable de la interioridad de todo individuo (de cualquier tipo); en toda individuación habitan disparidades metaestables ${ }^{24}$. Todo individuo constituye una sucesión permanente de individuaciones y toda individuación es posible en tanto coexisten elementos de disparidad en su resonancia interna: diferencias entre órdenes de magnitud metaestables que posibilitan la toma de forma por diferenciación. Atención a esta premisa. Una de las conclusiones transversales de la nueva episteme es que la no anulación de la alteridad -en la conciliación e integración metaestable- es condición de posibilidad de nuevas individuaciones:

La individuación que resuelve es la que conserva las tensiones en el equilibrio de la metaestabilidad en lugar de anularlas en el equilibrio de la estabilidad. La individuación vuelve compatible las tensiones, pero no las relaja; descubre un sistema de estructuras y funciones en el interior del cual las tensiones son compatibles (Simondon, 2009: 257).

\footnotetext{
${ }^{22}$ Dicha crisis se expresa desde la segunda década del s. XX con, además de los desarrollos de la mecánica cuántica, el principio de incertidumbre (principio complementariedad), la biología genética, la cibernética y la teoría de los sistemas, entre otros.

${ }^{23}$ Como un río que se parte en varios afluentes, las ciencias durante la modernidad se separaron y lanzaron a la conquista de la porción del mundo que le correspondía a cada una. Cada vertiente del río continuó su camino, generando sus propios avances, sorteando sus dificultades. Cada una, por su camino, fue confluyendo con las demás en las mismas categorías e identificando las mismas dinámicas en los trasfondos ontológicos (expresado en el alcance general de las categorías de información y comunicación). Hacía nuestros tiempos -primer cuarto del s. XXIresulta cada vez más notorio que las distintas vertientes del río fragmentado de la episteme moderna confluyen en una nueva episteme de mayor alcance integral (anunciada a mediados del s. XX por Simondon).

${ }^{24}$ Trasfondo complejo, contradictorio e indeterminado sobre lo cual se erige toda estabilidad. Desde Simondon, esto constituye una tendencia ampliable a los diferentes planos en que podamos concebir lo existente.
} 
En función de esto, volvamos a las analíticas del psicopoder. Siguiendo a Rouvroy y Burns (2016), los artilugios de la gubernamentalidad algorítmica logran operar en el carácter metaestable de lo psíquico infra-individual (por debajo de lo que el individuo reconoce como parte de sí mismo). Hablamos de un poder que interviene en lo pre-subjetivo, tendiendo a suscitar la inclinación antes que todo sentido o deseo subjetivante: "la gubernamentalidad algorítmica se alimenta de datos infra-individuales insignificantes por sí mismos, para ejecutar modelos de comportamiento o perfiles supra-individuales, sin apelar jamás al sujeto" (p. 97).

Sin embargo, el interpelamiento moral al individuo sigue siendo una estratagema presente tanto en los dispositivos de cancelación como en los de la gubernamentalidad algorítmica ${ }^{25}$. Los imperativos categóricos morales de nuestras sociedades actuales (rendimiento, transparencia, positividad, narcisismo y hedonismo), siguen apelando a un individuo que es discursivamente presentado e interpelado como totalidad, pero que es fácticamente desmembrado y licuado algorítmicamente en flujos de metadatos ${ }^{26}$ (Pasquinelli, 2011). La masividad de datos que arrojan nuestras vidas ampliamente mediadas por el ciberespacio y la elaboración de perfiles digitales continuamente actualizados- constituyen dos factores claves en la previsión y modulación de los comportamientos posibles.

Las nociones de dividual y transindividual serán mejor comprendidas de manera articulada. Ya en aquella enigmática Posdata a las sociedades de control, Deleuze (1991) anunciaba la emergencia de un poder cuya especificidad consiste en avanzar hacia lo dividual. En simples palabras podríamos afirmar que lo dividual refiere a la capacidad de las tecnologías digitales de dividir infinitamente una interioridad en términos de información (Muir, 2012). Al respecto, precisa y abre un interrogante Pablo Rodríguez (2019): "lo dividual nombra entonces ese largo proceso de mediación informacional, donde habrá que ver si el individuo resultante de la dividualización es

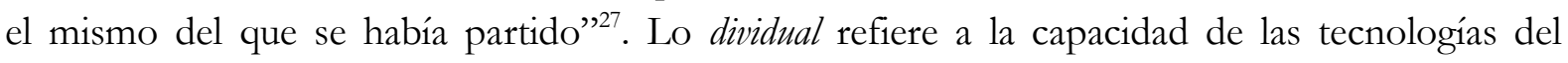
poder de desarrollar duplicaciones digitales milimétricas del mundo en términos de información (dobles estadísticos) y la capacidad de ejercer control desde dicha duplicación (tendiendo a que lo normativo emerja de lo social mismo).

Siguiendo a la nueva episteme, lo social y lo individual no existen en tanto términos absolutos que preceden a toda relación ${ }^{28}$. La relación no es entre términos preconstituidos, sino que la relación es constitutiva de los términos y -por lo tanto- es lo único que puede detentar rango de

\footnotetext{
${ }^{25}$ En este sentido afirman Rouvroy y Burns (2016) que “tendría más bien que ver con una rarefacción de los procesos y ocasiones propicios para una subjetivación, que con un fenómeno de "desubjetivación” o de puesta en peligro del individuo" (p. 103)

${ }^{26}$ Siguiendo Pasquinelli (2011), "se deben distinguir dos tipos de máquinas o algoritmos de información: algoritmos para traducir información en información (al codificar un flujo en otro flujo) y algoritmos para acumular información y extraer metadatos, es decir, para producir información sobre la información” ( $9^{\circ}$ Apartado).

${ }^{27}$ Rodríguez (2019) logra plasmar una excelsa sistematización de las distintas aristas que podrían desprenderse de lo dividual en el último capítulo de Las palabras en las cosas.

${ }^{28}$ Hay una evidente cercanía conceptual de la teoría de la individuación de Simondon con algunos de los planteos estructurales de cierto viraje epistemológico clave de la teoría social contemporánea durante el siglo XX. Nos referimos al estructural-constructivismo (Bourdieu, 2007; Giddens, 2003), el cual enfrentó las polarizaciones epistemológicas propias de los esencialismos (individualismo y holismo metodológico), reivindicando: la historicidad (con suma proximidad a la propuesta simondoniana de una episteme del devenir del ser, en lugar de una episteme que de por sentado el ser); y la integralidad (la categoría de habitus en Bourdieu -por ejemplo- logra dar cuenta de esa intersección donde no es posible distinguir con tanta claridad dónde termina lo psíquico y donde empieza lo social, o viceversa). En relación a la integralidad también es posible encontrar afinidades entre la propuesta epistémica simondoniana y la teoría de la complejidad (Morin, 2005; Rolando, 2006).
} 
ser. Todo atomismo no logra rasgar el velo de las apariencias y todo holismo se conforma con suposiciones metafísicas en torno a la ontologización de lo social. Según Simondon (2009):

Entre estos dos términos extremos se extiende la zona relacional oscura, la de lo colectivo real, cuya ontogénesis parece rechazada hacia lo incognoscible. Tomar la realidad de los grupos como un hecho, según la actitud de la objetividad sociológica, es llegar luego de la individuación que funda lo colectivo. Partir de los postulados interpsicológicos es situarse antes de la individuación del grupo (p. 398).

Es necesario situarse desde un pensamiento que no recaiga en la consideración de la relación entre términos extremos de "lo social puro" y "lo psíquico puro", sino en el carácter y los modos de las relaciones transversales que entrecruzan y configuran ambos registros, dando lugar a formas particulares en que se expresa lo social empírico. Lo transindividual es la individuación que "envuelve a los seres entre los cuales existe la relación y se manifiesta a través de la resonancia interna en el interior de lo colectivo" (p. 399).

La individuación psíquica y colectiva se encuentran entrelazadas por lo transindividual. En Simondon, además de lo técnico, lo emocional-afectivo es condición de integralidad de lo preindividual (metaestable) y lo transindividual: siendo que "la emoción es potencial que se descubre como significación al estructurarse en la individuación de lo colectivo" (p. 401). Ahora veremos de qué manera operan en estos procesos las tecnologías del psicopoder: fundamentalmente en lo que respecta a las técnicas de la gubernamentalidad algoritmica (su conductismo digital) y las tendencias en pos de la configuración de un inconsciente maquínico (Guattari, 1980).

Uno de los aspectos centrales de lo dividual refiere a la duplicación del mundo en datos: configuraciones múltiplemente entrelazadas de dobles estadísticos en continua actualización. De esta manera, el gobierno desde lo real parece concretarse (Foucault, 2006) y -al mismo tiempovolverse menos visible. La gubernamentalidad algorítmica integra técnicas de previsibilidad y performatividad $^{29}$. En sincronía con la línea trazada por Deleuze, tanto Pasquinelli como Rouvroy y Burns reconocen en los elementos vertebradores de la dinámica algorítmica: la tendencia hacía la captura del 'acontecimiento', 'el evento histórico', 'la singularidad'. Los dobles estadísticos interfieren formando parte intrínseca del mundo ${ }^{30}$, desde un conductismo digital y obturando toda singularidad; tendiendo hacia la autorreproducción de lo existente, la monologización de lo real.

Se interfiere dividualmente en lo pre-individual en dirección a la eliminación del principio de alteridad. Es decir, se busca obturar, capturar y modular el principio de alteridad proveniente de lo pre-individual. La proyección de la injerencia es hacia la normalización de toda inclinación en el registro de los posibles algorítmicamente asignados:

De lo que se esfuerza por excluir esta nueva manera de gobernar mediante algoritmos, es 'lo que podría advenir' y que no se había previsto porque justamente es fruto de disparidades (disparations), es decir la parte de incertidumbre, de virtualidad ${ }^{31}$, de potencialidad radical que

29 Performatividad que se expresa fundamentalmente en la "oferta [y no solo comercial] personalizada en función de propensiones no expresadas por el sujeto” (Rouvroy y Burns, 2016).

30 "No hay manera de sostener que el mundo "virtual", "informatizado", espejaría en todo lo que pueda al mundo "real", "material", porque todo estaría profundamente entrelazado; de allí que el término "comunidad virtual", referido a otra comunidad real, sea reemplazado por "red social", que asume que lo reticular va y viene de los dispositivos a las personas y viceversa” (Rodríguez, 2019: 354)

${ }^{31}$ Simondon ya había advertido de la imprecisión de la idea de virtualidad a la hora de reflexionar en torno a la preindividual.

Hipertextos, Vol. 9, N 16. Buenos Aires, Julio/Diciembre de 2021 «108 https://doi.org/10.24215/23143924e042, https://revistas.unlp.edu.ar/hipertextos 
hace que los seres humanos sean procesos libres de proyectarse, relacionarse, devenir sujetos, individuarse según trayectorias relativamente y relacionalmente abiertas (Rouvroy y Burns, 2016: 115).

El aprendiraje maquínico automatiza la dictadura del pasado, de taxonomías pasadas y de patrones de comportamiento sobre el presente. Este problema puede denominarse la regeneración de lo viejo: la aplicación de una visión homogénea de espacio-tiempo que restringe la posibilidad de un nuevo evento histórico (Pasquinelli y Joler, 2021: 11).

$\mathrm{El}$ aprendiraje maquínico, la gubernamentalidad algoritmica -y su conductismo digital- tienden hacia la eliminación de la alteridad desde lo dividual, sin necesidad de pasar por la mediación de sujetos conscientes o deseantes; operan en lo pre-individual (emocional-afectivo metaestable) buscando delimitar las individuaciones posibles y tendiendo a reproducir un inconsciente maquínico. Pasando en limpio, la eliminación de la alteridad/disparidad (disparatión), el obturamiento del advenimiento de lo singular, la captura del acontecimiento (Foucault, 1987), es principio ordenador de la dinámica algorítmica de las tecnologías del poder contemporáneas. Nada más cerca del imperativo moral de la positividad que también encontramos en los dispositivos de cancelación ${ }^{32}$. El horizonte de la eliminación de la alteridad corresponde a ambos.

Probablemente con los dispositivos de cancelación estemos ante la forma paradigmática -en nuestros tiempos- de eliminación de la alteridad en lo transindividual. Lo emocional-afectivo, aspecto constituyente de lo transindividual, ocupa también un rol fundante en los modos de operar (fundamentalmente en el contagio digital) de los dispositivos de cancelación. Si lo pensamos en términos paradigmáticos, la dinámica dividual algorítmica imposibilita el advenimiento de individuacionesotras fundamentalmente en lo que respecta a los sujetos, mientras que los dispositivos de cancelación configuran ciertos modos de individuación colectiva, impidiendo otros. Sin embargo, la dinámica dividual algorítmica también procura ciertos modos de individuación colectiva, impidiendo otros. Así también, los dispositivos de cancelación tienen implicancias y están entrelazados a elementos del devenir de individuaciones psíquicas de los sujetos. Esto es porque ambos operan en el registro de lo transindividual (zona relacional intermedia y centro ontológico de las individuaciones psíquicas y colectivas).

\section{Registro ideológico-cultural preponderante de los dispositivos de cancelación}

La pandemia del COVID-19 fue sin dudas una oportunidad para concretar aún más el desiderátum de la sociedad informatizada: "que la mayor cantidad posible de actividades realizadas de manera común y corriente sea transferida a un soporte digital" (Rodríguez, 2019, p. 349). Otra de sus consecuencias identificables es la profundización de la crisis categorial de los registros ideológicos izquierda-derecha. En no pocas sociedades occidentales fue posible identificar la preponderancia de discursos de izquierda en clave normativista (promoviendo el respeto de la legislación y administración pública pandémica) y desmovilizada/desmovilizante. Mientras tanto también vimos el surgimiento de una derecha insurgente (planteando el rechazo de las normatividades pandémicas) y -en algunos casos- movilizada.

\footnotetext{
$32 \mathrm{El}$ imperativo moral de la transparencia también ocupa un lugar fundamental en ambos.
} 
Los dispositivos de cancelación vienen cada vez más aparejados a un sentido común progresista con rasgos moralizantes. El registro ideológico de dichas discursividades puede recuperar elementos del liberalismo, la socialdemocracia y las nuevas izquierdas. Las causas pueden integrar reivindicaciones en torno al género, la raza, el especismo, entre las más destacadas. En relación a su afinidad con ciertas retóricas de izquierda, en una entrevista la psicoanalista Alexandra Kohan insinúa que se trata de "mucha neurosis haciéndose pasar por presión social" "33. Cada vez hay más llamados de atención en torno al peligro de la deriva neofascista de algunas fracciones del progresismo. Según Zizek (Jameson y Zizek, 1998): “hoy, el neofascismo es cada vez más posmoderno, civilizado y lúdico, y mantiene una autodistancia irónica, pero no por eso es menos fascista" (p. 162)

Creo en el potencial transformador, particularmente, del eco-feminismo o feminismo descolonial (Mendoza, 2014). Creo en la importancia de afrontar la crisis civilizatoria que estamos atravesando ${ }^{35}$ con una profunda transformación del vínculo que establece nuestra especie con todo cuanto la rodea (la cuestión ecosistémica es aquí nodal). También creo en la importancia de que finalmente, en el plano geopolítico mundial, las dinámicas estatales (y la autodeterminación de los pueblos) logren imponerse por encima de la esfera del capital financiero transnacional: construyendo caminares populares desde la triada Estado, producción y trabajo; en un proceso gradual y continuo de distribución de los frutos y placeres de esta tierra.

Poner a la luz de ciertas analíticas del poder el furor contemporáneo de la así llamada "cultura de la cancelación" no constituye una crítica a las luchas en las que diferentes agentes inscriben sus prácticas. Tal era el temor de Fisher (2019), quien advertía: "puede parecer como si -y el otro hará todo lo posible por reforzar este pensamiento- se está atacando también las luchas contra el racismo, el sexismo y el heterosexismo" (p. 4). Dejando a un lado el listado poco exhaustivo del escritor inglés, es necesario destacar que en todo caso lo que se expone a la crítica son cierto tipo de dinámicas colectivas que tienden a instalarse y generalizarse en nuestras sociedades, fundamentalmente de la mano de las tecnologías del psicopoder.

\section{Una propuesta de abordaje de la alteridad}

Los dispositivos de cancelación constituyen una propuesta práctica de abordaje de la alteridad. Ante la violencia de aquel otro disfuncional, la sociedad responde con más violencia. La irrupción de la violencia no es ejercida desde un afuera de la sociedad, sino que la misma es suscitada de su mismo seno. La muerte digital hacia la cual se orientan los dispositivos de cancelación, nos invita a reflexionar en torno a cierta idea implícita de que hay personas (y cada vez más) que merecen un

\footnotetext{
${ }^{33}$ https://www.clarin.com/viva/tamara-tenembaum-vs-alexandra-kohan-discutir-feminismo-escrachevictimizacion 0 ptlPi3oy.html. En relación al concepto de neurosis, como mencione: Kohan adscribe al psicoanálisis freudiano. Allí la neurosis consiste en un trastorno psicogénico cuyos síntomas colaboran a la recreación de dramas primigenios de la infancia, los cuales conducen a la reincidencia en estados de angustia y/o ansiedad (Freud, 2013). Deleuze y Guattari (1985), con interesantes críticas al psicoanálisis, reconocen una afinidad entre modalidades del poder postdisciplinario y el auge de estos padecimientos psíquicos.

${ }^{34}$ Sería interesante que Zizek (2021) pueda dilucidar el origen específicamente occidental, en términos civilizatorios, de los dispositivos de cancelación y los trasfondos que sostienen la retórica neofascista. Invitarlo, también, a empaparse en la lectura de filósofos latinoamericanos como Kusch (1976), Scannone (2009), Dussel (2007), entre otros, que podrían inclusive aportar a la superación del estancamiento civilizatorio europeo.

35 Para ampliar en ello: Nuestra América ante la encrucijada civilizatoria. Una aproximación a la crisis civilizatoria hegemónica global y los desafíos para la liberación", 2019. https://cronistaslatinoamericanos.com/nuestra-america-ante-laencrucijada-civilizatoria-una-aproximacion-a-la-crisis-hegemonica-global-y-los-desafios-para-la-liberacion-2/
} 
castigo permanente, irrevocable. Queda vedada la posibilidad de transformación del otro: posible espejo de la imposibilidad de considerar la transformación propia y la comunitaria.

Nuestra empatía tiene un límite. Nuestra capacidad de amor es fragmentaria (Fromm, 2002) y narcisista (Han, 2018b). El otro merece un castigo permanente. Eliminamos la posibilidad de redención. Está vedada la posibilidad de transformación del otro y -por espejamiento transindividual- la propia también. Cancelando al otro me libero de la posibilidad de transformar la violencia que hay en mí. Así, el castigo social digital se convierte en una herramienta de apañamiento y auto salvataje de mi rol ciudadano o en tanto integrante de una sociedad. Castigo al otro en pos del bien social, sin ocuparme -ni reconocer- la propia negatividad que habita en mí.

Los dispositivos de cancelación operan también gracias a la fetichización de las problemáticas sociales: alimentando la creencia implícita de que las mismas se resuelven expulsando a sujetos concretos, perpetradores del bien común; como quien cree que eliminando el síntoma se supera la enfermedad. En este sentido: la negación de la contradicción, la supresión de la alteridad, constituyen dinámicas con amplias similitudes a lo que desde algunas psicologías se reconoce como la "negación de la sombra" (Jung, 1995). Aquel señalante del mal (encarnado en un 'otro') de los dispositivos de cancelación, el aportante a la configuración de la muerte digital, pareciera detentar suma cercanía a la actitud psicológica de quien niega el propio mal (sombra) proyectándola en los demás.

Las perspectivas descoloniales, la filosofía de la liberación, brindan la posibilidad a las filosofías y ciencias sociales de recuperar elementos propios de cosmogonías-otras (que habitaron y habitan este planeta) frente a la actual crisis sistémica y encrucijada civilizatoria que atraviesa la humanidad. Resulta fundamental dar lugar a la posibilidad de contraponer a este rasgo característico occidental -en torno a la eliminación de la alteridad- algunos elementos interesantes de las cosmogonías precolombinas, budista, hindú, afro, egipcia, entre otras, para encontrar propuestas con mayor tendencia hacia la integración de los opuestos ${ }^{36}$.

Siguiendo a Dussel (1996), la alteridad radical constituye aquello que no puede ser integrado, la exterioridad de un proyecto que se pretende totalizador y absoluto como lo es la colonialidad moderna occidental. A diferencia de la sintesis moderna occidental, que suprime y subordina el elemento contradictorio bajo el orden de lo estable, la sincresis nos ofrece la posibilidad de lo bíbrido metaestable: una convivencia creativa de elementos en tensión ${ }^{37}$, lo cual posibilitaría individuaciones transindividuales-otras; es decir, nuevas posibilidades de lo social.

\footnotetext{
36 Esto no quiere decir que en otras civilizaciones no encontramos formas en dirección a la eliminación de la alteridad. Sin embargo, particularmente en las civilizaciones helénicas y grecocatólicas encontramos un marco filosófico general en dirección a la negación y supresión del opuesto: visible desde Sócrates y Platón (con sus planteos de un mundo de las ideas superior al mundo asequible con los sentidos); pasando por el catolicismo medieval (donde se ejerce la misma violencia contravitalista desde un relato religioso que se impone como absoluto); e incluyendo a la misma modernidad (donde dicha civilización se impone colonialmente al mundo y encumbra el prototipo de ser humano racional occidental).

${ }_{37}$ Cobrando suma utilidad la categoría de "tensiones creativas" de García Linera (2011).
} 


\section{Referencias}

Alfie, C. (2018). Rita Segato: El feminismo punitivista puede hacer caer por tierra una gran cantidad de conquistas. Agencia Paco Urondo. https://www.agenciapacourondo.com.ar/generos/rita-segato-el-feminismo-punitivistapuede-hacer-caer-por-tierra-una-gran-cantidad-de

Baudrillard, J. (1978). Cultura y simulacro. Editorial Kairós.

Baudrillard, J. (1999). Olvidar a Foucault. Pre-textos.

Becker, H. (2009). Outsiders: hacia una sociología de la desviación. Siglo XXI.

Bourdieu, P. (2007). El sentido práctico. Siglo XXI.

Bruno, Fernanda (2013). Máquinas de ver, modos de ser: vigilância, tecnologia e subjetividade. Sulina.

Ceseña, A. E. (1996). Tecnología y organización capitalista al final del s. XX. En Marini, R. M. y Millán, M. La teoría social latinoamericana. Tomo IV. Cuestiones contemporáneas. Ediciones El Caballito.

Cuello, N. y Disalvo, L. (2020). El virus de la cancelación. Revista Anfibia. http://revistaanfibia.com/ensayo/virus-la-cancelacion/

Deleuze, G. (1991). Posdata sobre las sociedades de control, en Christian Ferrer (Comp.) Ediciones Nordan. http://www.fundacion.uocra.org/documentos/recursos/articulos/Posdata-sobrelassociedades-de-control.pdf.

Deleuze, G. y Guattari, F. (1994). Mil mesetas. Pretextos.

Dussel, E. (1996) Filosofía de la liberación. Nueva América.

Dussel, E. (2007). Politica de la liberación: historia mundial y crítica. Trotta.

Fisher, M. (2019). Salir del castillo del vampiro. Catarsi. https://catarsimagazin.cat/sortint-delcastell-del-vampir/

Foucault, M. (1987). De la subversión del conocimiento. Fischer.

Foucault, M. (2002). Vigilar y castigar. Siglo XXI.

Foucault, M. (2006). Seguridad, territorio, población. Curso en el Collège de France: 1977-1978. Fondo de Cultura Económica.

Freud, S. (2013). Esquema del psicoanálisis. Obras completas (José Luis Etcheverry, trad.). XXIII Moisés y la religión monoteísta, Esquema del psicoanálisis y otras obras (1937-1939). Amorrortu Editores.

Fromm, E. (2002). El arte de amar. Paidós.

Garcia, L. (2011. Tensiones creativas de la revolución: la quinta fase del proceso de cambio. Vicepresidencia del Estado Plurinacional. Presidencia de la Asamblea Legislativa Plurinacional. https://www.bivica.org/files/tensiones-creativas.pdf

Giddens, A. (2003). La constitución de la sociedad. Bases para la teoría de la estructuración. Amorrortu editores.

Grosso, J. (2021). Cancelación, una tendencia que avanza y asume formas peligrosas de impugnación sobre obras y télam. https://www.telam.com.ar/notas/202104/551357-cancelacion.html

Guattari, F. (1980). Presentación del seminario de 9 de diciembre de 1980. Les seminaires de Felix Guattari. https://www.revue-chimeres.fr/IMG/pdf/801209.pdf

Han, B-C. (2014). La sociedad de la transparencia. Pensamiento Herder.

Han, B-C. (2018a). Psicopolitica. Pensamiento Herder.

Han, B-C. (2018b). La agonía del Eros. Pensamiento Herder. 
Jameson, F. y Zizek, S. (1998). Estudios culturales: reflexiones sobre el multiculturalismo. Paidós. Jung, C-G. (1995). El hombre y sus simbolos. Paidós.

Kusch, R. (1976). Geocultura del Hombre Americano. Fernando García Cambeiro.

Lazzarato, M. (2006). Politicas del acontecimiento. Tinta Limón.

Mariño, J. (2020). Qué es la cultura de la cancelación, la tendencia que puede destruir a alguien en pocos minutos. Infobae. https://www.infobae.com/sociedad/2020/07/11/que-es-la-culturade-la-cancelacion-la-tendencia-que-puede-destruir-a-alguien-en-pocos-minutos /

Martins, C. E. (2011). Globalización, dependencia y neoliberalismo en América Latina. Boitempo.

Mendoza, B. (2014). La epistemología del sur, la colonialidad del género y el feminismo latinoamericano. En Espinosa Miñoso, Gómez Correal, D. y Ochoa Muñoz, K. (eds.) Tejiendo de otro modo: Feminismo, epistemología y apuestas descoloniales en Abya Yala (pp. 91-104). Editorial Universidad del Cauca.

Morin, E. (2005). Introducción al pensamiento complejo. Gedisa.

Moscato, L. (2021). Qué es la cultura de la cancelación y qué significa estar "cancelado". La Nación. Revista Ohlala. https://www.lanacion.com.ar/revista-ohlala/cultura-de-lacancelacion-los-peligros-de-esta-nueva-practica-que-crece-nid29042021/

Muir, L. (2012). ¿Espacio de control? Representaciones cinematográficas del espacio de vigilancia entre disciplina y control. Universidad de Queen.

Pasquinelli, M. (2011). Capitalismo de la máquina y plusvalía de la red: notas sobre la economía política de la máquina de Turing. En Pasquinelli, Matteo (ed.). Gli algoritmi del capitale Accelerazionismo. Macchine della conoscenza e autonomia del comune. Ombre Corte.

Pasquinelli, M. y Joler, V. (2021). El Nooscopio de manifiesto. LaFuga, 25, 2021, ISSN: 07185316.

Pastor, J. (2020). Nuevo espíritu del capitalismo neoliberal, pensamiento positivo y la felicidad como imperativo. Cronistas Latinoamericanos. https://cronistaslatinoamericanos.com/nuevoespiritu-del-capitalismo-neoliberal-pensamiento-positivo-y-la-felicidad-como-imperativo/

Prueger, J. E. (2020). Las teorías del poder postdisciplinario (Tesis de grado). Presentada en Universidad Nacional de La Plata. Facultad de Humanidades y Ciencias de la Educación para optar al grado de Licenciado en Sociología.

Prueger, J. (2020b). Las teorías postdisciplinarias y el desafío de describir una nueva tecnología del poder. Revista Hipertextos, 8 (14), pp. 73-90. https://doi.org/10.24215/23143924e020

Roberts, D. (2010). Post-Truth Politics. Grist. https://grist.org/article/2010-03-30-post-truthpolitics/

Rodríguez, P. (2019). Las palabras en las cosas. Cactus.

Garcia, R. (2006). Sistemas complejos: conceptos, método y fundamentación epistemológica de la investigación interdisciplinaria. Gedisa.

Rouvroy, A. y Berns, T. (2016). Gubernamentalidad algorítmica y perspectivas de emancipación: ¿lo dispar como condición de individualización por relación? Revista ECOPOS, 18 (2). Tecnopolíticas e Vigilancia pp. 36-56.

Rullani, E. (2004). El capitalismo cognitivo: ¿un déjà-vu? En VV. AA. (2004). Capitalismo cognitivo, propiedad intelectual y creación colectiva. Traficante de sueños.

Scannone, J. (2009). La filosofía de la liberación: historia, características, vigencia actual. Teología y vida, 5 (1-2), 59-73.

Schwab, K. (2016). La cuarta revolución industrial. World Economic Forum: Debate.

Simondon, G. (2009). La individuación a la luz de las nociones de forma y de información. Cactus. 
Srnicek, N. (2018). Capitalismo de plataformas. Caja Negra

Tarde, G. (1986). La opinión y la multitud. Taurus.

Weber, M. (1979). La ética protestante y el espiritu del capitalismo. Premia.

Zizek, S. (2021). Mi manifiesto Europeo. Le Monde. Opiniones-Tribunas. https://www.lemonde.fr/idees/article/2021/05/13/slavoj-zizek-mon-manifesteeuropeen 6080078 3232.html

Zukerfeld, M. (2006). Bienes Informacionales y Capitalismo Cognitivo: Conocimiento, Información y Acceso en el siglo XXI. Razón y Palabra, 1-14. 